\title{
DIAGRID Generation Applied to X-shape Steel Tube of HSA800 with High Tensile Strength and Ductility
}

\author{
Dongkyu Lee \\ Department of Architectural Engineering, Sejong University, Seoul, South Korea
}

\section{Email address:}

dongkyulee@sejong.ac.kr

\section{To cite this article:}

Dongkyu Lee. DIAGRID Generation Applied to X-Shape Steel Tube of HSA800 with High Tensile Strength and Ductility. Applied and Computational Mathematics. Vol. 4, No. 6, 2014, pp. 452-455. doi: 10.11648/j.acm.20150406.18

\begin{abstract}
This article proposes DIAGRID structural details locked in X-formed steel tube using HSA 800 steel with high tensile strength and superior ductility as a modification of an original DIAGRID version. The structural effectiveness of the new structural DIAGRID detail information is presented in this study using actual nonlinear static pushover analysis.
\end{abstract}

Keywords: DIAGRID, HSA800, High Tensile Strength, Ductility, Structural System, Nonlinear Pushover Analysis

\section{Introduction}

A diagrid $[1,2,3]$ is formed by intersecting diagonal and horizontal components. This innovation transfers both gravity loads and lateral loads by redirecting member forces, and eliminates the need for vertical mega columns on the exterior of the building. Architecturally the absence of columns in the corners of the building enables great panoramic views and extends the useful space from the interior. The new structural system [4, 5] consists of a DIAGRID perimeter, which is composed of a network of multi-story tall triangulated truss systems. The first detailed structural analysis of DIAGRID was performed in 1932 [6], and the system was first introduced in the United States in Chicago's John Hancock Center [7], which was completed in 1969.

A specific design detail of DIAGRID structural systems was applied to the Cyclone Tower in Korea. It was considered by many engineers and designers to be an ideal DIAGRID due to its simplicity, as shown in Fig. 1. Nevertheless, the DIAGRID detail has various problems, including the interference of extended cap plates and stress concentrations at the end of tubes, and these have to be resolved.

In this study, a modified version of the original DIAGRID $[11,14]$ is considered as DIAGRID locked in X-shape tube of HSA800 steel without considering the interference of extended cap plates. One of the more recent developments of steels [12, 13] for construction is really a trend of developments given the term high performance. High performance steel materials provide far greater strength, ductility, durability, and resistance to external elements than traditional construction steels, and can significantly increase the longevity of structures in the built environment and can also reduce maintenance costs for these structures considerably.

High performance does not mean merely higher strength, but rather the improved performance of a number of varied factors of steels. For example, welding is used in most construction fabrication and therefore weldability is a significant factor. Many of the new construction steels ease the need for these precautions by producing high quality welds faster with less effort, with less consideration for pre-heat and post-heat and with less concern about internal cracking like lamellar tearing. Ductility is an ability that permits steel to elongate without fracture. Most of all strength is one of the key factors of high performance steels. Increased strength equates to reduced quantities of steel within limits of a given deformation, which may lead to reduced construction cost.

The high performance steels appeal to an optimal combination of improved features that more than make up for their higher specific cost. They provide opportunities to reduce the finished construction cost by lowering fabrication cost and, by reducing steel weight, the costs of shipping and erection. Much of the early research in these products was done for military use, which requires more functions rather than cost. Adapting this technology to building construction applications, along with essentially reducing material costs, gives an impulse to further develop steels.

This study is divided into 3 Sections. In Section 2 structural behaviors of innovative improved DIAGRID details are verified by numerical examples through structural 
analyses, using the ABAQUS commercial software package. The conclusions are presented in Section 3.

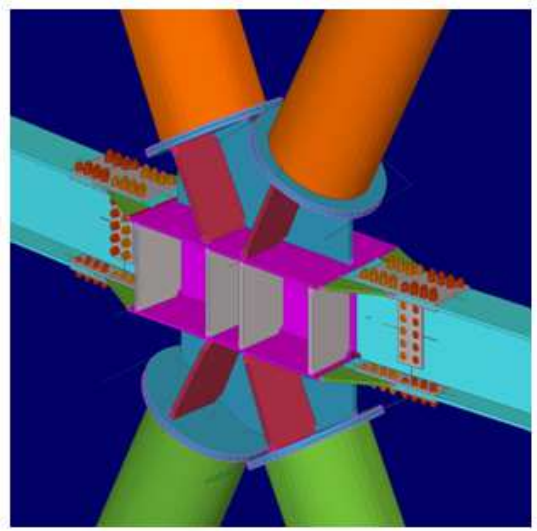

(a) 3D diagrid detail

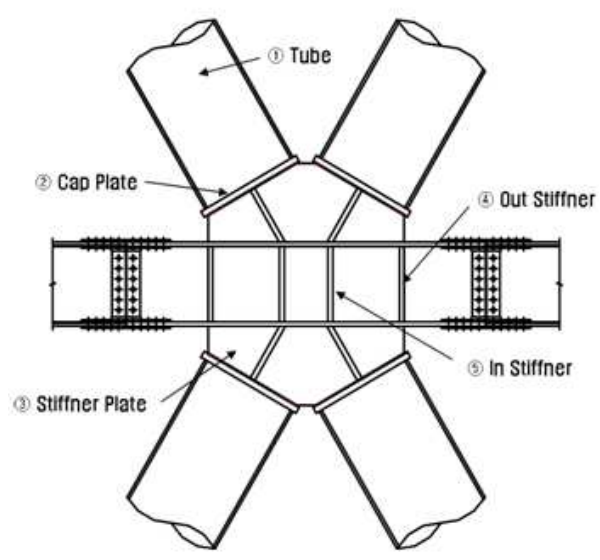

(b) Each member for diagrid detail

Figure 1. DIAGRID details for Cyclone Tower.

\section{Analytical Pushover Test and Measurement of Inventive Solutions}

In Section 2, structural behaviors of innovative improved DIAGRID details are verified by numerical examples through structural analyses, using the ABAQUS commercial software package.

Figures 2 and 3 show details of a modified DIAGRID, loading and support conditions and numerical modeling. Loading and support conditions follow author's study of original DIAGRID [11]. Fx1 of 502 tonf and Fx2 of 329 tonf are loaded as given forces of Cyclone Tower under fixed supports. Here, Fx2 is pre-stressed using pushover [8].

The test specimens of DIAGRID structures are defined in Table 1. In 2012, POSCO and RIST (Korea) developed a new high-performance rolled steel plate with $800 \mathrm{MPa}$ grade tensile strength for building structures called, HSA800. This Steel has upper and lower bounds for yield and ultimate tensile strength of $650 \sim 770 \mathrm{MPa}$ and $800 \sim 950 \mathrm{MPa}$, respectively. It was verified through material tests [9] and Korea Standard D 5994 [10].
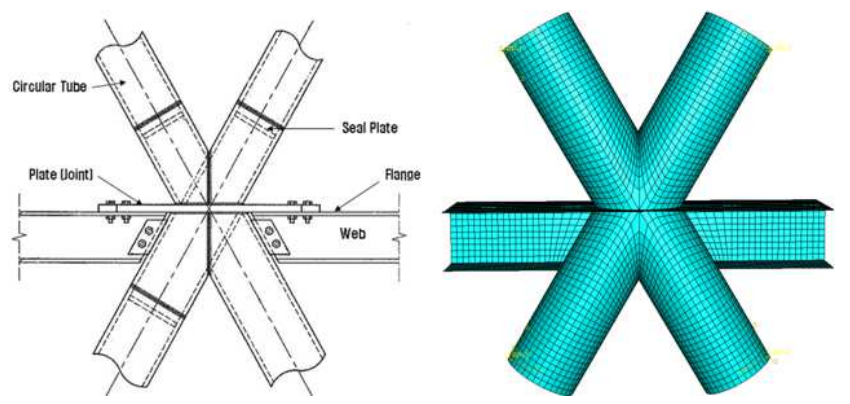

Figure 2. Details of a modified DIAGRD and numerical modeling.

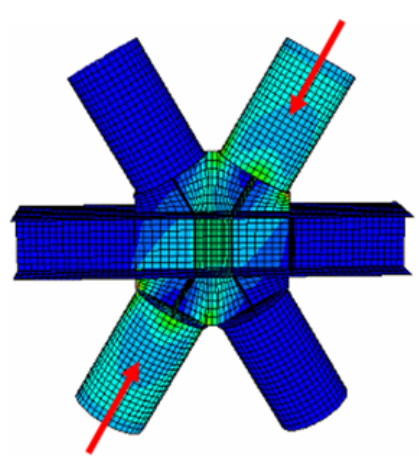

(a) Pre-loaded Fx1

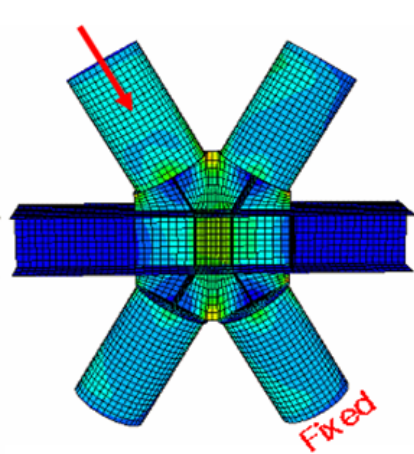

(b) Compressive load of Fx2
Figure 3. Design conditions of an original DIAGRID [11].

Table 1. Test specimens of DIAGRIDs.

\begin{tabular}{|c|c|c|c|c|c|c|c|c|}
\hline & $\begin{array}{l}\text { Diameter } \\
(\mathrm{mm})\end{array}$ & $\begin{array}{l}\text { Thickness } \\
(\mathrm{mm})\end{array}$ & Steel type & $\begin{array}{l}\text { Tensile strength } \\
\text { (MPa) }\end{array}$ & $\begin{array}{l}\text { Seal Plate } \\
\text { thickness }(\mathrm{mm})\end{array}$ & $\begin{array}{l}\text { Plate thickness } \\
(\mathrm{mm})\end{array}$ & $\begin{array}{l}\text { Flange thickness } \\
(\mathrm{mm})\end{array}$ & $\begin{array}{l}\text { Web thickness } \\
(\mathrm{mm})\end{array}$ \\
\hline Cross-1 & 600 & 12 & HSA 800 & 650 & 12 & 30 & 25 & 30 \\
\hline Cross-2 & 600 & 12 & SS400 & 240 & 12 & 30 & 25 & 30 \\
\hline Cross- 3 & 600 & 12 & SS400 & 240 & 30 & 30 & 25 & 30 \\
\hline Cross-4 & 600 & 12 & SS400 & 240 & 12 & 40 & 25 & 30 \\
\hline Cross-5 & 600 & 12 & SS400 & 240 & 12 & 30 & 25 & 40 \\
\hline
\end{tabular}

The current nominal value of 650 and 800 in Table 1 is the lowest value of the actual values. I considered the worst-case scenario for safety.

High performance steel HSA800 (High-performance rolled Steel for Architectural buildings with tensile stress of 800 $\mathrm{MPa}$ ) and SS400 (nominal value of the yield stress of 240
MPa) steel are used for DIAGRID material.

Figure 4 shows the load-displacement curves of a modified $\mathrm{X}$-shape DIAGRID. As can be seen, a higher slope of the curve indicates better stiffness and a lower slope means better ductility. In all cases of HSA800 and SS400, the great thickness of tube and plate produces the best stiffness, but the 
worst ductility in case of high strength steel of HSA800. From these results, it can be found that a thickness of tube and plate improves initial stiffness and the low strength steel of SS400 improves ductility in general.

Figure 5 describes the improvement of stiffness and ductility in a X-shape DIAGRID according to applying convex and concave DIAGRID [11]. In particular, compared with the existing flat DIAGRID controlling thickness and extension length of cap plates, it is verified that the convex DIAGRID in use of HSA800 steel is the best solution.

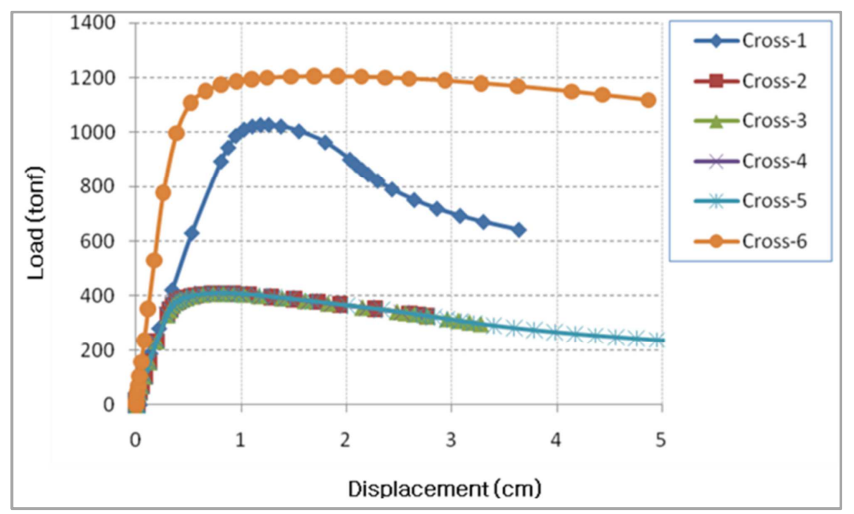

Figure 4. Load-displacement curve of a modified DIAGRID.

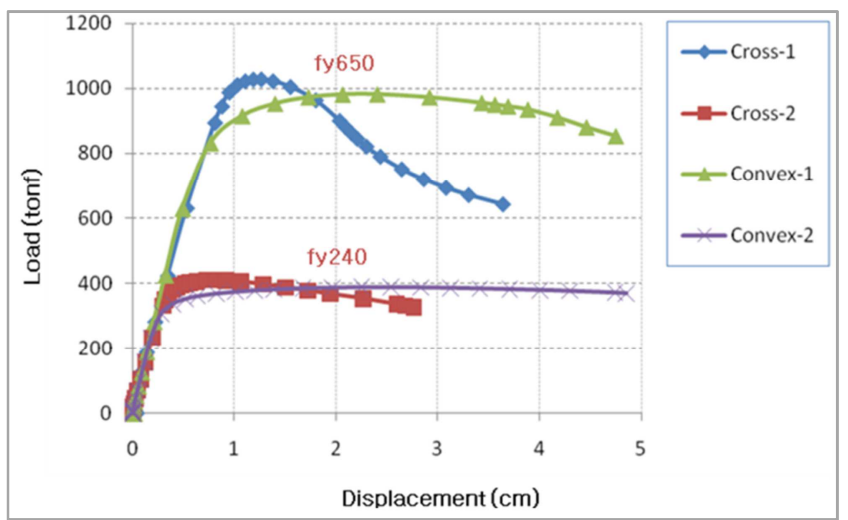

Figure 5. Load-displacement curve of original and X-shape DIAGRID.

Furthermore, a composite type of convex and concave forms, i.e., a ball type, may be proposed to obtain the best stiffness and ductility.

Figure 6 shows collapsed views of a X-shape DIAGRID using HSA800 steel. It can be seen that the X-shape DIAGRID distributes stresses all round, unlike the stress concentrations of the flat DIAGRID [11]. This means stress concentrations at the ends of tubes are relieved.

Figure 7 shows collapsed views of a X-shape DIAGRID using SS400 steel. The results are similar to those of Fig. 6.
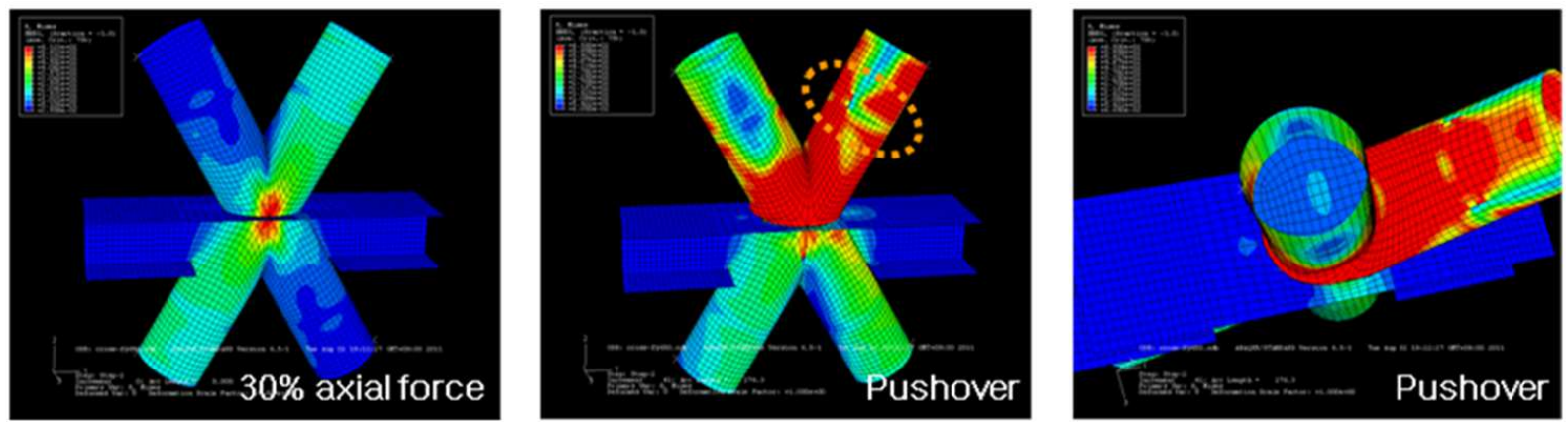

Figure 6. Collapsed views of a X-shape DIAGRID applying HSA800 steel.
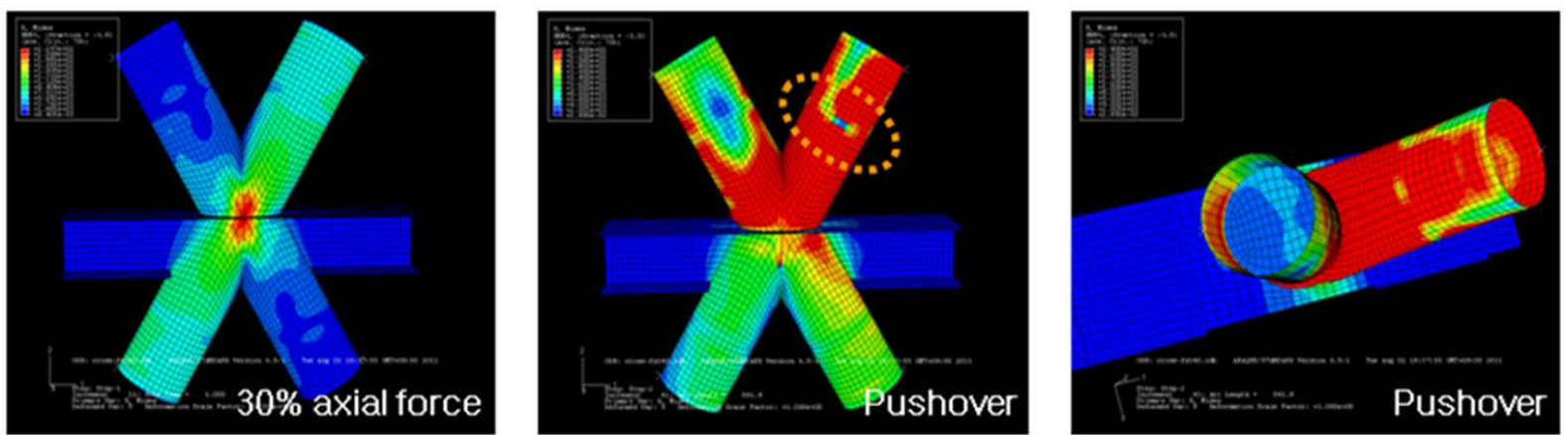

Figure 7. Collapsed views of a X-shape DIAGRID applying SS400 steel.

\section{Conclusions}

In this article, a convex DIAGRID with high strength steel, HSA800 is evaluated as being an improvement on the current best solution, i.e., flat shaped DIAGRID, and the structural and economic superiority of the convex DIAGRID is verified using the ABAQUS commercial software package for nonlinear static pushover analysis.

\section{Acknowledgements}

This research was supported by the 2013R1A1A2057502 from the National Research Foundation of Korea (NRF) funded by the Korea government. 


\section{References}

[1] D. K. Lee, J. H. Kim, I. H. Chang, U. Starossek, and S. M. Shin, "Conceptual Layouts and Angles of DiaGrid for Building Frames using Topological Optimization," Proceedings of the Tenth International Conference on Computational Structures Technology, Civil-Comp Press, Stirlingshire, UK, 2010, paper 317.

[2] K. S. Moon, "Sustainable Design of Diagrid Structural Systems for Tall Buildings," International Journal of Sustainable Building Technology and Urban Development, vol. 2(1), 2011, pp.37-42.

[3] M. M. Ali and K. S. Moon, "Structural Developments in Tall Buildings: Current Trends and Future Prospects," Architectural Science Review, vol. 50(3), 2007, pp.205-223.

[4] R. M. Kowalczyk, R. Sinn, and M. B. Kilmister, Structural systems for tall buildings, McGraw-Hill, New York, 1994.

[5] M. M. Ali, "The skyscraper: epitome of human aspirations," In proceedings of the $7^{\text {th }}$ World Congress of the Council on Tall Buildings and Urban Habitat: Renewing the Urban Landscape [CD-ROM], Chicago, IL: Council on Tall Buildings and Urban Habitat, 2005.

[6] I. McCain, DiaGrid - Structural Efficiency \& Increasing Popularity, 2006 , http://www.dsg.fgg.uni-lj.si/dubaj2009/.../Diagrid\%20technologij a.pdf.
[7] A. S. Zimmer and G. R. Bell, John Hancock Center Scaffold Collapse, ASCE Fourth Forensic Engineering Congress, 2006.

[8] R. R. Fayaz, R. M. Mohammad, and K. A. A. Nader, "Modal spectra combination method for pushover analysis of special steel moment resisting frames," International Journal of Civil Engineering, vol. 10(4), 2012, pp.245-252.

[9] D. H. Kim, S. E. Lee, and J. H. Kim, HSA800: High Strength Steel for Bldgs.: Material Properties and Cost-effectiveness, CTBUH $20129^{\text {th }}$ World Congress, 2012. pp.817.

[10] High-performance rolled Steel for building structures, Korea Standard D (KS D) 5994, 2012.

[11] D. K. Lee and S. M. Shin, "Advanced high strength steel tube diagrid using TRIZ and nonlinear pushover analysis," Journal of Constructional Steel Research, vol. 96, 2014, pp.151-158.

[12] B. Reidar, B, "Development and use of high performance steel," Journal of Constructional Steel Research, vol. 60(3-5), 2004, pp.393-400.

[13] M. S. Shih and W. P. Sung, "A model for hysteretic behaviour of rhombic low yield strength steel added damping and stiffness," Computers \& Structures, vol. 83(12-13), 2005, pp.895-908.

[14] D. K. Lee, J. H. Lee, J. H. Kim, and U. Starossek, "Investigation on Material Layouts of Structural Diagrid Frames by using Topology Optimization," KSCE Journal of Civil Engineering vol. 18(2), 2014, pp.549-557. 